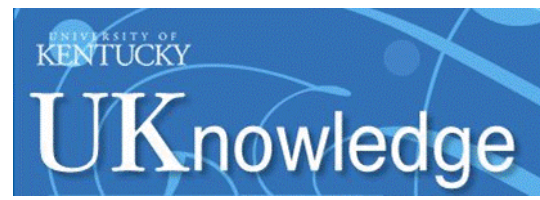

University of Kentucky

UKnowledge

Superfund Research Center Faculty Publications

4-1-2017

\title{
A Compromised Liver Alters Polychlorinated Biphenyl-Mediated Toxicity
}

\author{
Banrida Wahlang \\ University of Kentucky \\ Jordan T. Perkins \\ University of Kentucky \\ Michael C. Petriello \\ University of Kentucky, michaelcpetriello@gmail.com \\ Jessie B. Hoffman \\ University of Kentucky, jessie.hoffman@uky.edu \\ Arnold J. Stromberg \\ University of Kentucky, stromberg@uky.edu
}

See next page for additional authors

Follow this and additional works at: https://uknowledge.uky.edu/superfund_facpub

Part of the Environmental Health and Protection Commons, and the Toxicology Commons

Right click to open a feedback form in a new tab to let us know how this document benefits you.

\section{Repository Citation}

Wahlang, Banrida; Perkins, Jordan T.; Petriello, Michael C.; Hoffman, Jessie B.; Stromberg, Arnold J.; and Hennig, Bernhard, "A Compromised Liver Alters Polychlorinated Biphenyl-Mediated Toxicity" (2017). Superfund Research Center Faculty Publications. 7.

https://uknowledge.uky.edu/superfund_facpub/7

This Article is brought to you for free and open access by the Superfund Research Center at UKnowledge. It has been accepted for inclusion in Superfund Research Center Faculty Publications by an authorized administrator of UKnowledge. For more information, please contact UKnowledge@lsv.uky.edu. 
A Compromised Liver Alters Polychlorinated Biphenyl-Mediated Toxicity

Digital Object Identifier (DOI)

https://doi.org/10.1016/j.tox.2017.02.001

Notes/Citation Information

Published in Toxicology, v. 380, p. 11-22.

(๖ 2017 Elsevier B.V. All rights reserved.

This manuscript version is made available under the CC-BY-NC-ND 4.0 license

https://creativecommons.org/licenses/by-nc-nd/4.0/.

The document available for download is the author's post-peer-review final draft of the article.

Authors

Banrida Wahlang, Jordan T. Perkins, Michael C. Petriello, Jessie B. Hoffman, Arnold J. Stromberg, and Bernhard Hennig 


\title{
A Compromised Liver Alters Polychlorinated Biphenyl-Mediated Toxicity
}

\author{
Banrida Wahlang ${ }^{a, b}$, Jordan T. Perkins ${ }^{a}$, Michael C. Petriello ${ }^{a, b}$, Jessie B. Hoffman ${ }^{a, c}$, \\ Arnold J. Stromberg ${ }^{a, d}$, and Bernhard Hennig ${ }^{a, b, c,{ }^{*}}$ \\ aSuperfund Research Center, University of Kentucky, Lexington, KY, USA 40536 \\ bDepartment of Animal and Food Sciences, College of Agriculture, Food, and Environment, \\ University of Kentucky, Lexington, KY, USA 40536
}

'Graduate Center for Nutritional Sciences, College of Medicine, University of Kentucky, Lexington, KY 40536

dDepartment of Statistics, College of Arts and Sciences, University of Kentucky, Lexington, KY, USA 40536

\section{Abstract}

Exposure to environmental toxicants namely polychlorinated biphenyls (PCBs) is correlated with multiple health disorders including liver and cardiovascular diseases. The liver is important for both xenobiotic and endobiotic metabolism. However, the responses of an injured liver to subsequent environmental insults has not been investigated. The current study aims to evaluate the role of a compromised liver in PCB-induced toxicity and define the implications on overall body homeostasis. Male C57B1/6 mice were fed either an amino acid control diet (CD) or a methioninecholine deficient diet (MCD) during the 12-week study. Mice were subsequently exposed to either PCB126 (4.9 mg/kg) or the PCB mixture, Arcolor1260 (20 mg/kg) and analyzed for inflammatory, calorimetry and metabolic parameters. Consistent with the literature, MCD diet-fed mice demonstrated steatosis, indicative of a compromised liver. Mice fed the MCD-diet and subsequently exposed to PCB126 showed observable wasting syndrome leading to mortality. PCB126 and Aroclor1260 exposure worsened hepatic fibrosis exhibited by the MCD groups. Interestingly, PCB126 but not Aroclor1260 induced steatosis and inflammation in CD-fed mice. Mice with liver injury and subsequently exposed to PCBs also manifested metabolic disturbances due to alterations in hepatic gene expression. Furthermore, PCB exposure in MCD-fed mice led to extra-hepatic toxicity such as upregulated circulating inflammatory biomarkers, implicating endothelial cell dysfunction. Taken together, these results indicate that environmental pollution can exacerbate toxicity caused by diet-induced liver injury which may be partially due to dysfunctional

\footnotetext{
*To whom correspondence should be addressed: Bernhard Hennig, PhD, Rm. 501 Wethington Health Sciences Bldg, 900 S. Limestone Street, University of Kentucky, Lexington, KY40536-0200, Phone (859) 218-1387 or 218-1343, Fax (859) 257-1811, bhennig@uky.edu.

Conflict of interest

The authors declare they have no actual or potential competing conflict of interest relevant to this work.

Publisher's Disclaimer: This is a PDF file of an unedited manuscript that has been accepted for publication. As a service to our customers we are providing this early version of the manuscript. The manuscript will undergo copyediting, typesetting, and review of the resulting proof before it is published in its final citable form. Please note that during the production process errors may be discovered which could affect the content, and all legal disclaimers that apply to the journal pertain.
} 
energy homeostasis. This is relevant to PCB-exposed human cohorts who suffer from alcohol or diet-induced fatty liver diseases.

\section{Graphical abstract}

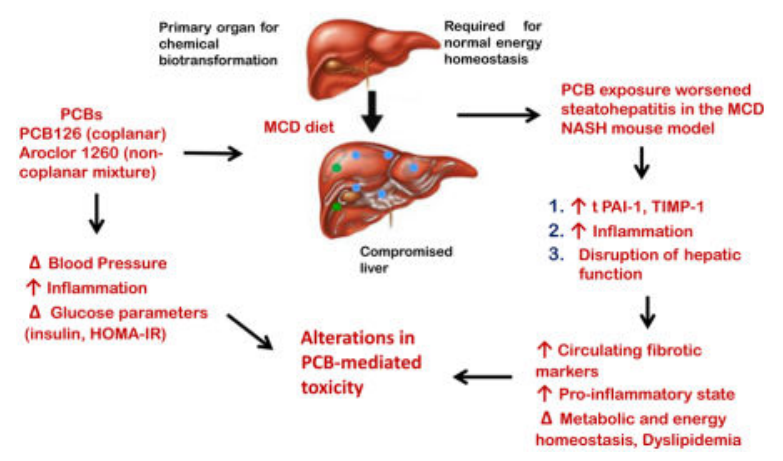

\section{Keywords}

PCB126; Aroclor1260; MCD; liver; steatohepatitis; toxicity

\section{Introduction}

Polychlorinated biphenyls (PCBs) are synthetic organochlorine compounds that were manufactured over three decades ago and used as dielectric fluids in electrical equipment. The global production of PCBs is estimated at 1.5 million tons with the United States being the single largest producer. PCB production in the United States was banned by the United States Congress in 1979 and worldwide in 2001 by the Stockholm Convention on Persistent Organic Pollutants (Xu et al. 2013). Despite being banned for over 30 years, the chemical and thermodynamic stability of PCBs allowed them to resist degradation and hence they still persist in the ecosystem. Exposure to persistent organic pollutants such as PCBs is positively correlated with increased risk of developing multiple diseased outcomes such as liver disease, hypertension, diabetes and vascular diseases (Cave et al. 2010; Perkins et al. 2016; Taylor et al. 2013). Based on their chemical structure, PCBs can be classified as either coplanar or non-coplanar. The coplanar PCBs are mostly the lower-chlorinated congeners that have less than one-ortho chlorine substitution in their phenyl ring while the noncoplanar ones have more than one-ortho substitutions and usually comprise of the higher chlorinated congeners. Furthermore, based on the structure of the specific congener, PCBs have also been proposed to bind and/or activate different receptors in the body, eventually leading to different pathological outcomes (Wahlang et al. 2014a). Animal studies have shown that coplanar PCB exposure is mostly associated with vascular cell dysfunction and inflammation (Petriello et al. 2014) while exposure to higher chlorinated, non-coplanar PCBs is associated with obesity and fatty liver disease (Wahlang et al. 2013; Wahlang et al. 2014b). Humans are exposed to multiple PCB congeners especially the heavily-chlorinated ones that are more resistant to degradation and thus, tend to persist in the ecosystem. Therefore, in the context of the human exposure paradigm, the presence of both classes of 
PCBs in the body may result in more complex health outcomes by affecting different organ systems.

The liver, being the primary site for xenobiotic detoxification, is the principal target organ for toxic effects induced by environmental pollutants including PCBs. However, the liver possesses additional functions such as maintaining energy homeostasis in the body attributed to its role in endobiotic metabolism (Rui 2014). Liver injury and liver diseases such as nonalcoholic fatty liver disease (NAFLD) and non-alcoholic steatohepatitis (NASH) have been linked to other health complications such as obesity, diabetes, insulin resistance and the metabolic syndrome (Firneisz 2014). Moreover, liver disease has been considered to be a risk factor for other disorders such as cardiovascular diseases (Bhatia et al. 2012; Magida and Leinwand 2014; Naschitz et al. 2000). In fact, NAFLD occurs worldwide and it is the most common form of liver disease in industrialized countries. In the United States, NAFLD accounts for $75 \%$ of chronic liver diseases and affects all ages (Hassan et al. 2014). Moreover, the liver is the site for PCB metabolism and any injury to the liver may compromise the ability of the body to metabolize and excrete these compounds, which could result in more deleterious effects exerted by the parent compound. Therefore, it is important to evaluate the effects of chemicals such a PCBs on a compromised liver and to determine if this would disrupt normal energy metabolism. This will allow us to better understand how crucial and relevant is the liver's role in mitigating the toxic effects of environmental pollutants. Furthermore, it will also identify interactions between the heart and extra-hepatic organ systems that may act cumulatively in exacerbating PCB toxicity and other health complications such as obesity and the metabolic syndrome.

In the current study, we aim to investigate the effects of PCB exposure in the presence of a compromised liver and evaluated hepatic and peripheral (extra-hepatic) toxicity endpoints. In order to test our hypothesis, mice were fed a methionine-choline deficient (MCD) diet to induce hepatic fibrosis and injury (Liu et al. 2013). Mice were then exposed to PCBs, either as a single congener (PCB126) or a mixture of congeners, using the commercial PCB mixture, Aroclor 1260. The results obtained from the study demonstrated that the liver is indeed crucial for maintenance of energy homeostasis in the body and that exposure of a compromised liver to different PCB congeners can consequently lead to severe toxicological outcomes.

\section{Materials and methods}

\subsection{Animals, diets and PCB exposure}

The animal protocol was approved by the University of Kentucky Institutional Animal Care and Use Committee. Eight week-old wild type male C57B1/6 mice were purchased form Taconic (Hudson, NY, USA). Mice were divided into 6 study groups $(n=10)$ based on either diet type, PCB126 exposure or Aroclor 1260 exposure during this 12-week study utilizing a $2 \times 3$ design. Mice were housed in a temperature- and light controlled-room (12 hour light; 12 hour dark) with food and water ad libitum. For the first two weeks, all animals received the amino acid control diet (CD; TD.94149; Harlan Teklad, Madison, WI, USA). Diet components are described in Supplementary Table 1. The groups designed to receive the methionine-choline deficient (MCD) diet were fed with the MCD diet (TD.90262, Harlan 
Teklad) from week 3 onwards. On week 6-7 and week 8-9, the MCD-fed mice were restored back to CD- feeding because of the excess weight loss that was non-compliant with the IACUC protocol. PCB126 or Aroclor1260 (both purchased from AccuStandard, CT, USA) was administered in corn oil by oral gavage (vs. corn oil alone). PCB126 $(2.45 \mathrm{mg} / \mathrm{kg}$ ) and Aroclor $1260(10 \mathrm{mg} / \mathrm{kg})$ were gavaged in two individualized doses on week 5 and week 7 to minimize acute toxicity, resulting in a cumulative dosage of $4.9 \mathrm{mg} / \mathrm{kg}$ for PCB126 and $20 \mathrm{mg} / \mathrm{kg}$ for Aroclor1260. The dosages selected were based on previous PCB studies (Newsome et al. 2014; Wahlang et al. 2016; Wahlang et al. 2014b) where PCB126 has been shown to induce inflammation in mouse models while Aroclor1260 resembled PCB levels found in a PCB-exposed human cohort. The different groups based on diet and exposure timelines are shown in Supplementary Fig. 1. After the second gavage was administered (week 7), some of the mice from the MCD+PCB126 group died (n=3). The rest of the mice were extremely sick and lethargic, and their body weight was under the weight limit required by the IACUC protocol (>20\% loss in body weight), hence they were subsequently euthanized at the end of week 8 . Due to their extremely low bodyweight, only their livers were collected for hepatic analysis. A glucose tolerance test was performed at week 10. During weeks 11-12, 5 mice were randomly selected from each group and placed in metabolic chambers (PhenoMaster, TSE systems, Chesterfield, MO, USA) overnight to assess food/water consumption and physical activity. Animals were euthanized (ketamine/ xylazine, $100 / 20 \mathrm{mg} / \mathrm{kg}$ body weight, i.p.) at the end of week 12 . Prior to euthanasia, the animals were analyzed for lean and body fat composition using the EchoMRI (EchoMRI LLC, Houston, TX, USA). Ethylenediaminetetraacetic acid was added to collected blood samples, briefly mixed, and centrifuged at $2000 \mathrm{~g}$ for $15 \mathrm{~min}$ at $4{ }^{\circ} \mathrm{C}$ to separate blood plasma. Plasma samples were frozen in liquid nitrogen and stored at $-80^{\circ} \mathrm{C}$ until processing. Tissues were harvested for mRNA or protein and stored at $-80^{\circ} \mathrm{C}$ prior to analysis. Thus, six different groups were evaluated; CD+vehicle, CD+PCB126, CD +Aroclor1260, MCD+vehicle, MCD+PCB126, MCD+Aroclor1260.

\subsection{Ultrasound imaging and blood pressure measurements}

On week 8, 2 mice were randomly chosen from each group and high-frequency ultrasound imaging was performed using the Vevo 2100 Imaging System (VisualSonics Inc., Toronto, Ontario, Canada) to determine the development/extent of liver steatosis and fibrosis (Fernandez-Dominguez et al. 2011). During imaging sessions, mice were kept under anesthesia using $1.5 \%$ isoflurane in oxygen and restrained on a heated stage. The mouse abdomen was depilated with commercial hair removal cream (Veet, Reckitt Benckifer, Granollers, Spain), and an ultrasound coupling gel was applied to the depilated skin. Images of the liver were acquired through the ventral body wall in transverse and sagittal orientations, employing a 40-MHz probe. Systolic and diastolic blood pressure measurements were measured using a non-invasive tail-cuff system (Coda 8; Kent Scientific Corporation, Torrington, CT, USA). The measurements were performed for four sequential days on week 11 of the study.

\subsection{Glucose tolerance test}

On the day of the test, mice were fasted for $6 \mathrm{~h}$ ( 6 a.m. -12 p.m.), and fasting blood glucose levels were measured with a hand-held glucometer (ACCU-CHECK Aviva, Roche, Basel, 
Switzerland) using 1-2 $\mu \mathrm{L}$ blood via tail snip. Glucose was then administered (1 mg glucose/g body weight, sterile saline, i.p.), and blood glucose was measured at 5, 15, 30, 60, 90 and 120 min post injection. Diabetic parameters including insulin resistance and insulin sensitivity were assessed. Insulin resistance was calculated by the homeostasis model assessment using the formula: homeostasis model assessment of insulin resistance (HOMAIR) =fasting glucose $(\mathrm{mg} / \mathrm{dL}) \times$ fasting insulin $(\mu \mathrm{U} / \mathrm{mL}) / 405$. Insulin sensitivity was assessed using the quantitative insulin sensitivity check index (QUICKI) as follows: QUICKI=1/[log (fasting insulin) $+\log$ (fasting glucose $)]$, and HOMA- $\beta=[(360 \times$ fasting insulin $) /($ fasting glucose-63)] $\%$.

\subsection{Histological studies}

Sections from the liver and adipose tissue were fixed in $10 \%$ neutral buffered formalin and embedded in paraffin for routine histological examination. Tissue sections were stained with hematoxylin-eosin (H\&E) or for chloroacetate esterase activity [CAE, Naphthol AS-D Chloroacetate (Specific Esterase) Kit, Sigma Aldrich, St. Louis, MO, USA] and examined by light microscopy. Photomicrographic images were captured using a high-resolution digital scanner at 10x and 40x magnification.

\subsection{Cytokine and adipokine measurement}

The Milliplex Map Mouse Adipokine Magnetic Bead Panel (Millipore Corp, Billerica, MA, USA) was utilized to measure plasma cytokines (tumor necrosis factor alpha (Tnfa), interleukin-6 (IL-6), macrophage chemoattractant protein-1 (Mcp-1)), insulin, adipokines (leptin, resistin), and plasminogen activator inhibitor-1 (PAI-1); while the Milliplex Map Mouse CVD Magnetic Bead Panel 1 was used to measure plasma CVD markers on the Luminex Xmap MAGPIX system (Luminex Corp, Austin, TX, USA), as per the manufacturer's instructions.

\subsection{Real-time PCR}

Mouse liver samples were homogenized and total RNA was extracted using the TRIzol reagent (Thermo Fisher Scientific Inc, Waltham, MA, USA). RNA purity and quantity were assessed with the NanoDrop 2000/2000c (Thermo Fisher Scientific Inc) using the NanoDrop 2000 (Installation Version 1.6.198) software. cDNA was synthesized from total RNA using the QuantiTect Reverse Transcription Kit (Qiagen, Valencia, CA, USA). Polymerase chain reaction (PCR) was performed on the CFX96 Touch Real-Time PCR Detection System (Bio-Rad, Hercules, CA, USA) using the Taqman Fast Advanced Master Mix (Thermo Fisher Scientific Inc). Primer sequences from Taqman Gene Expression Assays (Thermo Fisher Scientific Inc) were as follows: tumor necrosis factor alpha (Tnfa); (Mm00443258_m1), plasminogen activator inhibitor (PAI-1, serpine 1); (Mm00435858_m1), tissue inhibitor of metalloproteinase 1 (Timp-1); (Mm01341361_m1), (NAD(P)H dehydrogenase, quinone 1 (Nqo1); (Mm01253561_m1), heme oxygenase 1 (Hmox1); (Mm00516005_m1), fatty acid synthase (Fas); (Mm00662319_m1), peroxisome proliferator-activated receptor alpha (Ppara); (Mm00440939_m1), carnitine palmitoyl transferase 1A (Cpt1a); (Mm01231183_m1), phosphoenolpyruvate carboxykinase 1 (Pepck-1); (Mm01247058_m1), glucose-6-phosphatase (G6Pase); (Mm00839363_m1), cytochrome P450s [Cyp2b10(Mm01972453_s1), Cyp3a11 (Mm00731567_m1), Cyp1a2 
(Mm00487224_m1)], flavin containing monooxygenase 3 (Fmo3); (Mm01306345_m1), cluster of differentiation 36 (Cd36) (Mm01135198_m1), beta actin (Actb); (Mm02619580_g1), natriuretic peptide type A (ANF, Nppa); (Mm01255748_g1), fibroblast growth factor 21 (Fgf21); (Mm00840165_g1), and peptidylprolyl isomerase A (Ppia); (Mm02342430_g1). The levels of mRNA were normalized relative to the amount of Actb and Ppia mRNA for liver and heart respectively, and expression levels in mice fed control diet and administered vehicle were set at 1 . Gene expression levels were calculated according to the $2^{-\Delta \Delta \mathrm{Ct}}$ method (Livak and Schmittgen 2001).

\subsection{Statistical Analysis}

Statistical analyses were performed using the JMP statistical software version 12.0 (SAS Institute Inc., Cary, NC). Graphs were plotted using GraphPad Prism version 6.07 for Windows (GraphPad Software Inc., La Jolla, CA, USA). Data are expressed as mean \pm SEM. For 2 group comparison, an unpaired t-test was used. Multiple group data were compared using One Way ANOVA followed by Tukey's post-hoc test while interactions between diet and either PCB126 or Aroclor 1260 exposure were calculated using the Fit Least Square Model. $P<0.05$ was considered statistically significant. All statistical analyses were overseen by biostatisticians at the University of Kentucky.

\section{Results}

\subsection{PCB exposure exacerbated liver injury induced by the MCD diet}

The MCD-fed groups developed steatosis and potentially hepatic fibrosis by week 8 of the study as determined by non-invasive, ultrasound imaging (Supplementary Fig. 2). Overall, the CD-fed mice showed homogeneous liver parenchyma and regular liver surface.

Echogenicity which is the ability of the surface to bounce back an echo or signal and reflects the degree of steatosis and fibrosis was also determined. The MCD-fed mice appeared to have irregular liver surfaces and increased echogenicity. The liver surface also showed hyperechoic areas $v s$. the $\mathrm{CD}$ groups, indicating fatty infiltration. Body composition analysis revealed that the MCD groups had a higher lean mass composition than the $\mathrm{CD}$ groups while they had a lower body fat composition as well (Supplementary Fig. 3).

Hepatic steatosis was assessed histologically while hepatic inflammation was assessed by liver weight, histology, serum cytokine and hepatic gene expression measurements. All MCD groups exhibited steatosis (H\&E staining) consistent with previous reports. Interestingly, PCB126 induced steatosis in the CD-fed mice but this was absent in the Aroclor1260-exposed mice (Fig. 1A). Body weight was measured throughout the 12-week study for 5 of the 6 groups and for 8 weeks for the MCD+PCB126 group. PCB126 and Aroclor1260 exposure decreased bodyweight in the MCD groups (Fig. 1B). There was a significant interaction between PCB126 and the MCD diet $(p=0.0219)$ resulting in exacerbated weight loss. During the study, PCB126 induced mortality $(n=3)$ in the MCD-fed mice on Week 7. The rest of the mice displayed signs of wasting, lethargy, and $>20 \%$ loss in body weight, therefore they were subsequently euthanized on week 8. Hence the MCD + PCB126 group was absent in most experimental analysis. The liver weight to body weight (LW/BW) ratio was calculated and all the MCD-fed mice developed steatosis by the end of 
the study (Fig. 1C). However, the LW/BW was greatest in the MCD+PCB126 group (significant interaction, $p=0.001$ ).

Scattered inflammatory foci with neutrophil infiltration were observed on CAE stained liver sections for all the MCD groups while the PCB126-exposed mice showed signs of hepatic inflammation in the CD groups (Fig. 2A). Hepatic Tnfa expression was significantly increased in all the MCD-fed mice while only the PCB126-exposed mice showed increased hepatic Tnfa among the CD-fed groups (Fig. 2B). Hepatic expression of fibrotic markers including PAI-1 and Timp-1 were also measured (Fig. 2C \& D). PCB126 increased hepatic PAI-1 and Timp-1 mRNA levels irrespective of the diet type given while Aroclor1260 exposure slightly increased PAI- 1 levels in the MCD group. MCD diet feeding also increased the hepatic expression of Timp-1. Circulating PAI-1 and Mcp-1 levels were also upregulated with PCB126 exposure in the CD-fed mice (Supplementary Fig. 4). Although we were unable to measure plasma PAI-1 levels in the MCD+PCB126 group, we anticipated upregulated levels as well based on the hepatic PAI-1 expression in these mice.

\subsection{Effects of MCD diet and PCB exposure on hepatic gene expression}

Because MCD feeding induced fatty liver disease and the mice livers were further exploited with PCB exposure, we evaluated liver function by measuring hepatic expression of genes involved in lipid metabolism and oxidative stress. Hepatic mRNA levels of Ppara and Cpt1a, both involved in fatty acid oxidation, were measured (Fig. 3A \& B). Aroclor1260 exposure increased Ppara expression in the CD group while PCB126 decreased its expression and this was significant in the MCD group. A similar observation was seen in Cpt1a expression. Interestingly, the MCD diet decreased Cpt1a expression as well. Cd36, a fatty acid translocase was also assessed and PCB126 upregulated $C d 36$ expression in the CD group (Fig. 3C). However, PCB126 negatively regulated $C d 36$ expression in the MCD group, indicating a significant interaction between diet and PCB126 ( $p=0.001)$. MCD diet itself upregulated $C d 36$ expression, a phenomenon seen in late stage MCD feeding (Park et al. 2011). Fas was also measured and its expression was decreased with PCB126 exposure in both diet groups (Fig. 3D). The hepatic expression of anti-oxidative genes, Nqo1 and Hmox-1, was also assessed (Fig. 3E \& F). Exposure to PCB126 increased hepatic expression of both Nqo1 and Hmox-1 while there was no effect with Aroclor1260 exposure. There was a significant interaction between MCD feeding and PCB126 for increased $\mathrm{Nqo1}$ expression $(p=0.002)$.

\subsection{Cardiovascular assessment}

In order to assess cardiac parameters, cardiac gene expression was evaluated. The combination of a compromised liver and PCB exposure could hamper cardiac function as well as induce injury on the related vasculature, hence we initially measured systolic blood pressure in these animals. The non-invasive blood pressure measurements were performed on week 11 of the study and hence only 5 groups were left. MCD feeding appeared to increase blood pressure with or without Aroclor 1260 exposure, indicative of hypertension in these groups. The $\mathrm{CD}+\mathrm{PCB} 126$ group had lower systolic blood pressure readings compared to the CD mice (Fig. 4A). Cardiac expression of selected genes that play a role in heart injury were evaluated and included the fibroblast growth factor ( Fgf21, protective in cardiac 
hypertrophy) and atrial natriuretic peptide ( $A N F$, counter high blood pressure) (Fig. 4B \& C). The cardiac expression of $F g f 21$ was decreased in the CD+PCB126 as well as the MCD groups but Aroclor 1260 had no effect. On the other hand, $A N F$ expression was increased with Aroclor 1260 exposure. Additionally, plasma levels of early markers of endothelial dysfunction namely, intracellular adhesion molecule (ICAM-1), platelet endothelial cell adhesion molecule (Pecam-1), P-Selectin and thrombomodulin were measured (Fig. 4D-G). Interestingly, all the plasma CVD markers were upregulated in MCD-fed mice exposed to Aroclor 1260 and there was a significant interaction between diet and Aroclor 1260 exposure for ICAM-1 ( $p=0.003)$ and thrombomodulin $(p=0.0006)$.

\subsection{Metabolic assessment: Effects on glucose metabolism, energy expenditure and adipokines}

The liver is also involved in maintaining carbohydrate homeostasis, hence we hypothesized that the induced liver injury may also disrupt glucose metabolism. Therefore, glucose tolerance, insulin resistance/sensitivity, pancreatic insulin secretion, and serum adipokines were measured. Fasting blood glucose levels were measured prior to performing the glucose tolerance test (Fig. 5A). The CD+PCB126 group appeared to have lower fasting blood glucose levels versus the Aroclor1260-exposed counterparts. The glucose tolerance test showed that the $\mathrm{CD}+\mathrm{PCB} 126$ group also had improved glucose tolerance/glucose uptake versus other groups as measured by the Area Under the Curve (AUC) (Fig. 5B). In order to evaluate if these animals suffered from insulin resistance, we measured fasting plasma insulin levels and calculated the HOMA-IR as an index of insulin resistance (Fig. 5C \& D). Interestingly, the MCD feeding led to decreased insulin levels which was decreased further with Aroclor1260 exposure. In fact, these mice showed no signs of insulin resistance (HOMA-IR) and instead demonstrated improved insulin sensitivity (QUICKI) (Fig. 5E). There was a significant interaction between MCD feeding and Aroclor1260 on the calculated insulin sensitivity ( $p=022)$. However, HOMA- $\beta$ which is a function of pancreatic cell function showed that both MCD and MCD+Aroclor1260 groups had lower HOMA- $\beta$ levels, indicating decreased pancreatic insulin secretion in these groups (Fig. 5F).

Furthermore, the hepatic expression of two gluconeogenic enzymes (Pepck-1) and glucose-6-phosphatase (G6Pase) were measured (Fig. 5G \& H). PCB 126 decreased hepatic expression Pepck-1 in the CD-fed mice while both genes were downregulated in the MCDfed mice with either PCB126 or Aroclor1260 exposure.

To assess the overall energy metabolism, mice were placed in metabolic cages and various metabolic parameters were evaluated. The MCD feeding significantly influenced energy expenditure as well as carbohydrate and lipid utilization. Oxygen consumption (vO2) and carbon dioxide production ( $\mathrm{vCO} 2)$ were monitored throughout the metabolic study and the respiration exchange rate (RER, vCO2/vO2) was calculated (Supplementary Fig. 5). The RER which is an estimate of the respiratory quotient, indicates whether the fuel source/ energy expenditure originated from carbohydrate or lipid metabolism. An RER of 0.70 suggests that fat is predominantly utilized, whereas an RER of 0.85 suggests a mix of fat and carbohydrate as the fuel source. MCD feeding resulted in lower RER indicating that lipid was the major fuel source for these animals. Interestingly, Aroclor1260 exposure increased RER versus $\mathrm{PCB} 126$ in the CD-fed mice. The total energy expenditure (EE) was computed 
using the modified Weir equation: $\mathrm{EE}=(3.815+1.232 \times \mathrm{RER}) \times \mathrm{VO} 2$ and $\mathrm{MCD}$ feeding also lowered EE irrespective of PCB exposure. Movement/physical activity was also assessed utilizing beam breaks in the metabolic chambers. There was no difference in movement/physical activity during the light cycle between the groups. However PCB126 exposure increased physical activity during the dark cycle. Interestingly MCD-fed mice did not show any compromise in physical activity despite the observed decrease in energy expenditure. Additionally, these mice did not show a decrease in food consumption either but the Aroclor1260-exposed mice had a higher water intake (data not shown). Aroclor1260 exposure increased total food intake in the CD-fed mice, possibly explaining the increase in RER. Furthermore, plasma adipokines were measured to better understand the metabolicrelated factors regarding PCB exposure and MCD feeding (Supplementary Fig. 6). Plasma leptin levels were significantly lower with MCD feeding but plasma resistin levels were not affected. However, Aroclor1260 exposure upregulated plasma resistin levels in the CD group.

\subsection{PCB-hepatic receptor interactions}

A number of studies have established PCB activation of many hepatic receptors such as the AhR as well as other nuclear receptors (CAR, PXR). In this study, we were interested in evaluating the effects of PCB exposure on the hepatic expression of these receptors' target genes. Hepatic expression of Cyp1a2, Fmo3 (AhR targets), Cyp2b10 (CAR target) and Cyp3a11 (PXR target) were measured. PCB126 exposure induced Cyp1a2 hepatic expression while Aroclor1260 had no effect (Fig. 6A). Additionally, MCD feeding had no effect on Cyp1a2 hepatic expression either. Similar to Cyp1a2, PCB126 also induced Fmo3 expression irrespective of the dietary group (Fig. 6B). Intriguingly, MCD feeding itself appeared to induce Fmo3 mRNA levels versus CD feeding. Aroclor 1260 exposure but not PCB126 upregulated Cyp2b10 expression while MCD diet had no effect whatsoever (Fig. 6C). In contrast, MCD feeding increased the basal expression of Cyp3a11 (Fig. 6D). Aroclor1260 also induced Cyp3a11 expression but only in the MCD group (Diet $\times$ Aroclor1260 interaction, $p=0.039$ ). On the other hand, PCB126 appeared to have a negative effect on the Cyp3a11 expression in MCD-fed mice (Diet $\times$ PCB126 interaction, $p=0.007$ ), although there was no PCB126 effect in the CD group.

\section{Discussion}

The current study evaluated and assessed the toxicological consequences of having a compromised liver with concomitant persistent organic pollutant exposure. It is well documented that PCB exposure is correlated with elevated liver enzymes that are biomarkers of liver injury (Cave et al. 2010). Moreover, it has been demonstrated that PCB exposure in animal models led to hepatic steatosis and non-alcoholic steatohepatitis in conjunction with a high fat diet (Wahlang et al. 2013; Wahlang et al. 2014b). Animal studies have also demonstrated that PCB exposure can lead to endothelial cell dysfunction and vascular inflammation (Petriello et al. 2014). Moreover, NAFLD/NASH is considered as an independent CVD risk factor with defective heart-liver communication exacerbating CVD (Baskin et al. 2014; Bhatia et al. 2012). Hence, in the current study, we used a NASH mouse model to mimic an injured hepatic state and then exposed the mice to PCBs. This is more or 
less a "two-hit" theory where liver injury acts as a first hit and environmental pollutant exposure as the second hit. We then evaluated hepatic, cardiovascular and metabolic parameters to test our hypothesis.

It is pertinent to note that PCBs vary in structure with structure-activity relationship studies denoting different receptor interactions between "coplanar or dioxin-like" and "non-coplanar or phenobarbital-like" PCBs (Luthe et al. 2008). In the current study, we employed two different sets of PCBs, one being PCB126 which is a prototypical "dioxin-like" congener and the other being the PCB mixture, Aroclor1260. PCB126 has been identified as an inducer of inflammation and oxidative stress that mediates its toxicity through the AhR. The PCB mixture, Aroclor1260, is composed primarily of non-coplanar PCBs with coplanar PCB composition approximating 1\% (Wahlang et al. 2014a). Studies on PCB mixtures such as Aroclors have focused primarily on obesity, diabetes and hepatic diseases that are mostly attributed to PCB-nuclear receptor (CAR, PXR) interactions, indicating different pathological outcomes than coplanar PCBs (Gray et al. 2013; Wahlang et al. 2016). Therefore, this study is the first to evaluate PCB effects on the liver-peripheral axis, taking into consideration the PCB planarity. Also, previous mouse studies on PCB126 were aligned with shorter exposure time points, hence the aftermath of chronic PCB126 exposure is yet to be evaluated.

In our study, NASH and hepatic fibrosis were evident using ultrasound imaging after 6 weeks of feeding the MCD diet, and this was accompanied by a decrease in percent fat composition (accompanied by decreased plasma leptin) and a concomitant increase in percent lean tissue mass. One of the key findings was the severe toxicity of PCB126 in the NASH group resulting in wasting and mortality during the study period. The combination of MCD+PCB126 contributed to more severe overall toxicity than MCD+Aroclor1260, suggesting that in a compromised liver state, PCB 126 remained a major contributor to further liver injury/toxicity. Interestingly, the dose of PCB126 chosen for this study was previously used in C57Bl/6 mice to induce pro-inflammatory response but not wasting syndrome, clearly indicating that the hepatic machinery was already compromised during the gavage period. On the contrary, PCB126 did not induce mortality in the CD-fed mice at the given dose. Furthermore, Aroclor $1260(20 \mathrm{mg} / \mathrm{kg})$ did not induce mortality in the NASH group. Indeed, PCB126 and Aroclor1260 appeared to induce different pathological states in these animals in both the CD and MCD groups. Steatohepatitis in the NASH groups was worsened with both PCB126 and Aroclor 1260 exposures (H\&E staining, CAE staining, hepatic Tnfa induction). PCB126 appeared to induce mild steatosis and inflammation in the CD groups. PCB126 was also a stronger mediator of both hepatic and systemic inflammation versus Aroclor1260. This discrepancy may be explained partially through PCB-receptor activation. PCB126 is a potent AhR inducer (Cypla2 and Fmo3 induction) but does not appear to interact with murine CAR and PXR while Aroclor 1260 activated CAR and to a lesser degree, PXR. Activation of the classical AhR signaling pathway induced the AhR target gene battery involved in xenobiotic metabolism and oxidative stress (Cyp1a2, Nqo1 and Hmox-1) while immune responses (cytokine induction) occur though the noncanonical pathway in relation with nuclear factor kappa B (NF-кB) (Vogel et al. 1997; Vogel et al. 2014). Per contra, PXR has a reciprocal relationship with NF- $\kappa B$ wherein they mutually repress each other while some observations have implied CAR basal repression 
activity on NF- $\mathrm{kB}$ signaling (Gerbal-Chaloin et al. 2013; Zhou et al. 2006). Therefore, CAR and PXR may negatively impact inflammation. Because Aroclor 1260 activated CAR and PXR, this effect on inflammation can lead to attenuation of Aroclor1260-induced toxicity. Nonetheless, the MCD+Aroclor1260 group manifested signs of hepatic inflammation, implicating that other mechanisms may be involved other than CAR/PXR activation.

Although they are xenobiotic receptors, AhR, CAR and PXR are involved in endobiotic and overall energy metabolism as well as associated with NAFLD (Lu et al. 2015; Naik et al. 2013; Wada et al. 2009). Moreover, the model focused on PCB effects on a compromised liver, thus it was appropriate to measure hepatic expression of genes involved in lipid metabolism. MCD feeding suppressed Cpt1a levels and appeared to have lower energy expenditure and RER. Aroclor1260 exposure upregulated Ppara and Cpt1a expression with no effect on Fas expression, consistent with previous findings (Wahlang et al. 2016). The mRNA levels of these metabolic genes were drastically reduced in the MCD+PCB126 group of mice which is a compelling observation, indicating complete breakdown of the hepatic machinery in these mice. Interestingly, PCB126 exposure in the CD-fed mice led to decreased Cpt1a and increased Cd36 mRNA levels implying a state of compromised lipid oxidation and increased lipid uptake that can mechanistically explain the observed hepatic fat accumulation in this group. In addition to hepatic effects, we also elucidated effects on glucose metabolism. PCBs, either as individual congeners or PCB mixtures have been shown to affect glucose uptake, insulin levels and gluconeogenic gene expression with arbitrary reports that are dependent on the dose, congener or mixture evaluated (Gray et al. 2013; Wahlang et al. 2016). In the current study, PCB126 appeared to induce hypoglycemia (lower fasting blood glucose and AUC levels). "Dioxin-like" PCBs have been shown to negatively regulate the rate-limiting gluconeogenic gene, phosphoenolpyruvate carboxykinase (Pepck-I) which may in part explain this distinct observation (Zhang et al. 2012). PCB126 had no effect on plasma insulin levels and insulin resistance/sensitivity. MCD feeding appeared to improve insulin resistance/sensitivity which is an established effect but paradoxical to NASH and a reported drawback of the MCD model (Imajo et al. 2013). However, Aroclor 1260 exposure significantly increased insulin sensitivity in the MCD-fed mice which was counterintuitive since this group displayed no improvement in plasma glucose levels and displayed decreased gluconeogenic gene expression. This group also exhibited decreased pancreatic insulin secretion and could be attributed to pancreatic cell dysfunction that occurred with PCB exposure (Jensen et al. 2014; Zhang et al. 2015). However more studies concerning toxicant exposure and pancreatic function are needed to further comprehend the mechanisms associated with this phenomenon.

With regards to extra-hepatic effects, BP assessment denoted PCB126 as a hypotensive agent in the CD mice while MCD diet feeding caused increase in systolic BP. Also, cardiac Fgf21 expression was lower in the MCD groups. Emerging studies have implicated the protective role of $F g f 21$ against cardiac hypertrophy and oxidative stress (Planavila et al. 2015; Planavila et al. 2013). However, there was no evidence of atherosclerosis. It can be speculated that the study duration was not sufficient to observe the PCB effects on cardiac function and the heart. Interestingly, mice with a compromised liver and exposed to Aroclor1260 displayed signs of endothelial cell dysfunction (increased plasma ICAM-1, PSelectin and thrombomodulin). Furthermore, studies on PCB exposure and hypertension are 
scarce, with only a few epidemiologic studies showing associations between plasma PCBs and increased risk for hypertension (Donat-Vargas et al. 2015; Park et al. 2016). Recently, a study by our group has reported an increase in hepatic Fmo3 expression with "dioxin-like" PCBs, thereby implicating these pollutants as risk factors for CVD (Petriello et al. 2016). To reiterate those previous findings, $F m o 3$ was measured in our study and it was upregulated with chronic PCB126 exposure. PCB126 also upregulated plasma levels and hepatic expression of PAI-1. Elevated PAI-1 is a risk factor for thrombosis and atherosclerosis since this serine protease inhibitor prevents breakdown of fibrin clots (Rouch et al. 2015). Nonetheless, in this study, the effect of PCBs on CVD renders more in-depth and mechanistic studies. Additionally, the current findings implicated that utilizing lower doses of PCBs and prolonging the study duration may allow us to further assess extra-hepatic endpoints such as CVD.

Overall, PCBs either as an individual congener or a mixture of congeners worsened liver injury induced by the MCD diet. Notably, different receptor targets were induced that led to different toxicity outcomes, indicating dose and congener-dependent receptor activation. This is a crucial factor considering that all types of PCBs are in the realm of the human exposome, and therefore human exposure can result in a combination of variable outcomes. The study evidently pointed out pollutant exposure as key mediators of inflammation and that environment pollutants can further perturb metabolic parameters, thus ameliorating metabolic derangements accordingly. However, the fact that MCD+PCB126 group were euthanized at an earlier time point than the other groups is a major limitation of the study, and poses as a confounding factor. In summary, an animal model simulating human NASH was utilized to study effects of PCB exposure both on the hepatic and peripheral (extrahepatic) system. The results of the current study shed some light in terms of comprehending the consequences of chronic pollutant exposure on an already compromised liver.

\section{Supplementary Material}

Refer to Web version on PubMed Central for supplementary material.

\section{Acknowledgments}

The authors would like to acknowledge Dr. Wendy Katz (COBRE Research Core) for assisting with the metabolic cages; Dr. Jessica Moorleghen, Dr. Anju Balakrishnan and Dr. Travis Sexton (Saha Cardiovascular Research Center) for assisting with the ultrasound imaging procedure, blood pressure measurements and MAGPIX operation respectively; and Dr. Andrew Morris (Core B, UK Superfund Research Center) for providing input on available resources.

Funding

The current study is supported by the NIEHS/NIH grant P42ES007380 and NIGMS/NIH grant 8 P20 GM103527-06.

\section{Abbreviations}
AhR
aryl hydrocarbon receptor
ANF
natriuretic peptide type A 


\begin{tabular}{|c|c|}
\hline $\mathbf{A U C}$ & area under the curve \\
\hline $\mathbf{B P}$ & blood pressure \\
\hline CAE & chloroacetate esterase \\
\hline CAR & constitutive androstane receptor \\
\hline CD & control diet \\
\hline Cd36 & cluster of differentiation 36 \\
\hline Cpt1a & carnitine palmitoyl transferase $1 \mathrm{a}$ \\
\hline Сур & cytochrome P450 \\
\hline $\mathbf{E E}$ & energy expenditure \\
\hline Fas & fatty acid synthase \\
\hline Fmo3 & flavin monooxygenase 3 \\
\hline Fgf21 & fibroblast growth factor 21 \\
\hline G6Pase & glucose-6-phosphatase \\
\hline H\&E & hematoxylin-eosin \\
\hline Hmox-1 & heme oxygenase 1 \\
\hline HOMА- $\beta$ & homeostasis model assessment of $\beta$-cell function \\
\hline HOMA-IR & homeostasis model assessment of insulin resistance \\
\hline ICAM-1 & intracellular adhesion molecule 1 \\
\hline IL-6 & interleukin-6 \\
\hline $\mathbf{L W / B W}$ & liver weight to body weight \\
\hline MCD & methionine-choline deficient diet \\
\hline Mcp-1 & macrophage chemoattractant protein-1 \\
\hline NAFLD & non-alcoholic fatty liver disease \\
\hline NASH & nonalcoholic steatohepatitis \\
\hline Nqo1 & (NAD(P)H dehydrogenase, quinone 1 \\
\hline PCBs & polychlorinated biphenyls \\
\hline PCR & polymerase chain reaction \\
\hline Pepck-1 & phosphoenolpyruvate carboxy kinase \\
\hline Ppar & peroxisome proliferator-activated receptor \\
\hline
\end{tabular}




$\begin{array}{ll}\text { PXR } & \text { pregnane-xenobiotic receptor } \\ \text { QUICKI } & \text { quantitative insulin sensitivity check index } \\ \text { RER } & \text { respiration exchange rate } \\ \text { SEM } & \text { standard error mean } \\ \text { Timp-1 } & \text { tissue inhibitor of metalloproteinase 1 } \\ \text { Tnfa } & \text { tumor necrosis factor alpha } \\ \text { PAI-1 } & \text { plasminogen activator inhibitor 1 }\end{array}$

\section{References}

Baskin KK, Bookout AL, Olson EN. The heart-liver metabolic axis: defective communication exacerbates disease. EMBO Mol Med. 2014; 6:436-438. [PubMed: 24623378]

Bhatia LS, Curzen NP, Calder PC, Byrne CD. Non-alcoholic fatty liver disease: a new and important cardiovascular risk factor? Eur Heart J. 2012; 33:1190-1200. [PubMed: 22408036]

Cave M, Appana S, Patel M, Falkner KC, McClain CJ, Brock G. Polychlorinated biphenyls, lead, and mercury are associated with liver disease in American adults: NHANES 2003-2004. Environ Health Perspect. 2010; 118:1735-1742. [PubMed: 21126940]

Donat-Vargas C, Gea A, Sayon-Orea C, de la Fuente-Arrillaga C, Martinez-Gonzalez MA, BesRastrollo M. Association between dietary intake of polychlorinated biphenyls and the incidence of hypertension in a Spanish cohort: the Seguimiento Universidad de Navarra project. Hypertension. 2015; 65:714-721. [PubMed: 25646299]

Fernandez-Dominguez I, Echevarria-Uraga JJ, Gomez N, Luka Z, Wagner C, Lu SC, Mato JM, Martinez-Chantar ML, Rodriguez-Cuesta J. High-frequency ultrasound imaging for longitudinal evaluation of non-alcoholic fatty liver disease progression in mice. Ultrasound Med Biol. 2011; 37:1161-1169. [PubMed: 21645964]

Firneisz G. Non-alcoholic fatty liver disease and type 2 diabetes mellitus: the liver disease of our age? World J Gastroenterol. 2014; 20:9072-9089. [PubMed: 25083080]

Gerbal-Chaloin S, Iankova I, Maurel P, Daujat-Chavanieu M. Nuclear receptors in the cross-talk of drug metabolism and inflammation. Drug Metab Rev. 2013; 45:122-144. [PubMed: 23330545]

Gray SL, Shaw AC, Gagne AX, Chan HM. Chronic exposure to PCBs (Aroclor 1254) exacerbates obesity-induced insulin resistance and hyperinsulinemia in mice. J Toxicol Environ Health A. 2013; 76:701-715. [PubMed: 23980837]

Hassan K, Bhalla V, El Regal ME, HHAK. Nonalcoholic fatty liver disease: a comprehensive review of a growing epidemic. World J Gastroenterol. 2014; 20:12082-12101. [PubMed: 25232245]

Imajo K, Yoneda M, Kessoku T, Ogawa Y, Maeda S, Sumida Y, Hyogo H, Eguchi Y, Wada K, Nakajima A. Rodent models of nonalcoholic fatty liver disease/nonalcoholic steatohepatitis. Int J Mol Sci. 2013; 14:21833-21857. [PubMed: 24192824]

Jensen TK, Timmermann AG, Rossing LI, Ried-Larsen M, Grontved A, Andersen LB, Dalgaard C, Hansen OH, Scheike T, Nielsen F, Grandjean P. Polychlorinated biphenyl exposure and glucose metabolism in 9-year-old Danish children. J Clin Endocrinol Metab. 2014; 99:E2643-2651. [PubMed: 25093617]

Liu Y, Meyer C, Xu C, Weng H, Hellerbrand C, ten Dijke P, Dooley S. Animal models of chronic liver diseases. Am J Physiol Gastrointest Liver Physiol. 2013; 304:G449-468. [PubMed: 23275613]

Livak KJ, Schmittgen TD. Analysis of relative gene expression data using real-time quantitative PCR and the 2(-Delta Delta C(T)) Method. Methods. 2001; 25:402-408. [PubMed: 11846609]

Lu P, Yan J, Liu K, Garbacz WG, Wang P, Xu M, Ma X, Xie W. Activation of aryl hydrocarbon receptor dissociates fatty liver from insulin resistance by inducing fibroblast growth factor 21 . Hepatology. 2015; 61:1908-1919. [PubMed: 25614121] 
Luthe G, Jacobus JA, Robertson LW. Receptor interactions by polybrominated diphenyl ethers versus polychlorinated biphenyls: a theoretical Structure-activity assessment. Environ Toxicol Pharmacol. 2008; 25:202-210. [PubMed: 19768137]

Magida JA, Leinwand LA. Metabolic crosstalk between the heart and liver impacts familial hypertrophic cardiomyopathy. EMBO Mol Med. 2014; 6:482-495. [PubMed: 24567073]

Naik A, Belic A, Zanger UM, Rozman D. Molecular Interactions between NAFLD and Xenobiotic Metabolism. Front Genet. 2013; 4:2. [PubMed: 23346097]

Naschitz JE, Slobodin G, Lewis RJ, Zuckerman E, Yeshurun D. Heart diseases affecting the liver and liver diseases affecting the heart. Am Heart J. 2000; 140:111-120. [PubMed: 10874271]

Newsome BJ, Petriello MC, Han SG, Murphy MO, Eske KE, Sunkara M, Morris AJ, Hennig B. Green tea diet decreases PCB 126-induced oxidative stress in mice by up-regulating antioxidant enzymes. J Nutr Biochem. 2014; 25:126-135. [PubMed: 24378064]

Park HS, Jeon BH, Woo SH, Leem J, Jang JE, Cho MS, Park IS, Lee KU, Koh EH. Time-dependent changes in lipid metabolism in mice with methionine choline deficiency-induced fatty liver disease. Mol Cells. 2011; 32:571-577. [PubMed: 22083307]

Park SH, Lim JE, Park H, Jee SH. Body burden of persistent organic pollutants on hypertension: a meta-analysis. Environ Sci Pollut Res Int. 2016

Perkins JT, Petriello MC, Newsome BJ, Hennig B. Polychlorinated biphenyls and links to cardiovascular disease. Environ Sci Pollut Res Int. 2016; 23:2160-2172. [PubMed: 25877901]

Petriello MC, Han SG, Newsome BJ, Hennig B. PCB 126 toxicity is modulated by cross-talk between caveolae and Nrf2 signaling. Toxicol Appl Pharmacol. 2014; 277:192-199. [PubMed: 24709675]

Petriello MC, Hoffman JB, Sunkara M, Wahlang B, Perkins JT, Morris AJ, Hennig B. Dioxin-like pollutants increase hepatic flavin containing monooxygenase (FMO3) expression to promote synthesis of the pro-atherogenic nutrient biomarker trimethylamine $\mathrm{N}$-oxide from dietary precursors. J Nutr Biochem. 2016; 33:145-153. [PubMed: 27155921]

Planavila A, Redondo-Angulo I, Ribas F, Garrabou G, Casademont J, Giralt M, Villarroya F. Fibroblast growth factor 21 protects the heart from oxidative stress. Cardiovasc Res. 2015; 106:19-31. [PubMed: 25538153]

Planavila A, Redondo I, Hondares E, Vinciguerra M, Munts C, Iglesias R, Gabrielli LA, Sitges M, Giralt M, van Bilsen M, Villarroya F. Fibroblast growth factor 21 protects against cardiac hypertrophy in mice. Nat Commun. 2013; 4:2019. [PubMed: 23771152]

Rouch A, Vanucci-Bacque C, Bedos-Belval F, Baltas M. Small molecules inhibitors of plasminogen activator inhibitor-1 - an overview. Eur J Med Chem. 2015; 92:619-636. [PubMed: 25615797]

Rui L. Energy metabolism in the liver. Compr Physiol. 2014; 4:177-197. [PubMed: 24692138]

Taylor KW, Novak RF, Anderson HA, Birnbaum LS, Blystone C, Devito M, Jacobs D, Kohrle J, Lee DH, Rylander L, Rignell-Hydbom A, Tornero-Velez R, Turyk ME, Boyles AL, Thayer KA, Lind L. Evaluation of the association between persistent organic pollutants (POPs) and diabetes in epidemiological studies: a national toxicology program workshop review. Environ Health Perspect. 2013; 121:774-783. [PubMed: 23651634]

Vogel C, Donat S, Dohr O, Kremer J, Esser C, Roller M, Abel J. Effect of subchronic 2,3,7,8tetrachlorodibenzo-p-dioxin exposure on immune system and target gene responses in mice: calculation of benchmark doses for CYP1A1 and CYP1A2 related enzyme activities. Arch Toxicol. 1997; 71:372-382. [PubMed: 9195019]

Vogel CF, Khan EM, Leung PS, Gershwin ME, Chang WL, Wu D, Haarmann-Stemmann T, Hoffmann A, Denison MS. Cross-talk between aryl hydrocarbon receptor and the inflammatory response: a role for nuclear factor-kappaB. J Biol Chem. 2014; 289:1866-1875. [PubMed: 24302727]

Wada T, Gao J, Xie W. PXR and CAR in energy metabolism. Trends Endocrinol Metab. 2009; 20:273279. [PubMed: 19595610]

Wahlang B, Falkner KC, Clair HB, Al-Eryani L, Prough RA, States JC, Coslo DM, Omiecinski CJ, Cave MC. Human receptor activation by aroclor 1260, a polychlorinated biphenyl mixture. Toxicol Sci. 2014a; 140:283-297. [PubMed: 24812009]

Wahlang B, Falkner KC, Gregory B, Ansert D, Young D, Conklin DJ, Bhatnagar A, McClain CJ, Cave M. Polychlorinated biphenyl 153 is a diet-dependent obesogen that worsens nonalcoholic fatty liver disease in male C57BL6/J mice. J Nutr Biochem. 2013; 24:1587-1595. [PubMed: 23618531] 
Wahlang B, Prough RA, Falkner KC, Hardesty JE, Song M, Clair HB, Clark BJ, States JC, Arteel GE, Cave MC. Polychlorinated Biphenyl-Xenobiotic Nuclear Receptor Interactions Regulate Energy Metabolism, Behavior, and Inflammation in Non-alcoholic-Steatohepatitis. Toxicol Sci. 2016; 149:396-410. [PubMed: 26612838]

Wahlang B, Song M, Beier JI, Cameron Falkner K, Al-Eryani L, Clair HB, Prough RA, Osborne TS, Malarkey DE, Christopher States J, Cave MC. Evaluation of Aroclor 1260 exposure in a mouse model of diet-induced obesity and non-alcoholic fatty liver disease. Toxicol Appl Pharmacol. 2014b; 279:380-390. [PubMed: 24998970]

$\mathrm{Xu} \mathrm{W}$, Wang X, Cai Z. Analytical chemistry of the persistent organic pollutants identified in the Stockholm Convention: A review. Anal Chim Acta. 2013; 790:1-13. [PubMed: 23870403]

Zhang S, Wu T, Chen M, Guo Z, Yang Z, Zuo Z, Wang C. Chronic Exposure to Aroclor 1254 Disrupts Glucose Homeostasis in Male Mice via Inhibition of the Insulin Receptor Signal Pathway. Environ Sci Technol. 2015; 49:10084-10092. [PubMed: 26190026]

Zhang W, Sargis RM, Volden PA, Carmean CM, Sun XJ, Brady MJ. PCB 126 and other dioxin-like PCBs specifically suppress hepatic PEPCK expression via the aryl hydrocarbon receptor. PLoS One. 2012; 7:e37103. [PubMed: 22615911]

Zhou C, Tabb MM, Nelson EL, Grun F, Verma S, Sadatrafiei A, Lin M, Mallick S, Forman BM, Thummel KE, Blumberg B. Mutual repression between steroid and xenobiotic receptor and NFkappaB signaling pathways links xenobiotic metabolism and inflammation. J Clin Invest. 2006; 116:2280-2289. [PubMed: 16841097] 


\section{Highlights}

- $\quad$ Polychlorinated biphenyls (PCBs) are persistent environmental contaminants that are associated with multiple health disorders including liver diseases, diabetes and cardiovascular diseases.

- $\quad$ PCBs comprised of over 200 congeners based on chlorine atom substitution and exposure to different congeners can lead to different diseased outcomes.

- The current study utilizes a fibrotic-mouse model to study the behavior of PCBs, either as a single congener (PCB126) or a mixture of congeners (Aroclor1260).

- $\quad$ PCB exposure in mice that already have an injured or compromised liver worsen overall inflammation and disrupted normal liver function. 
A

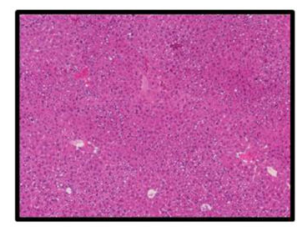

CD

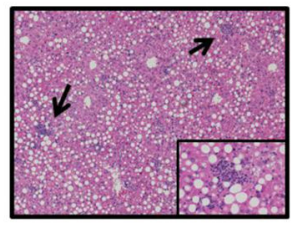

MCD

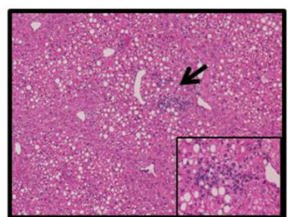

CD+PCB126

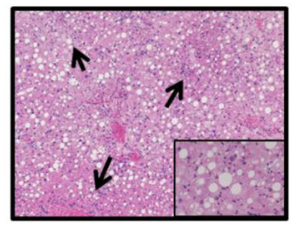

MCD+PCB126

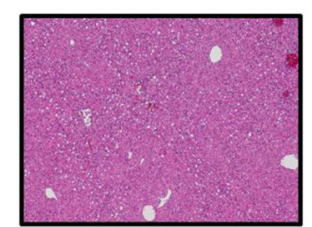

CD+Aroclor1260

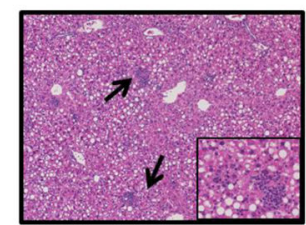

MCD+Aroclor1260
B

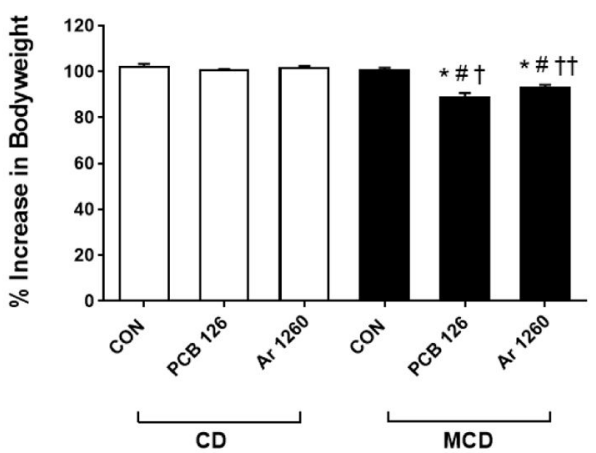

C

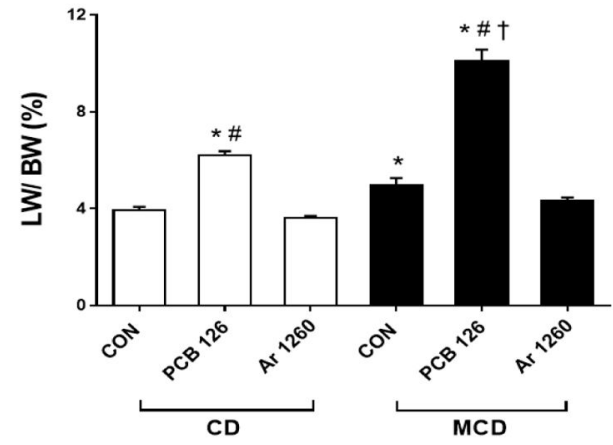

Figure 1. Effects of PCB126 and Aroclor1260 exposure on steatosis and body weight (A) H\&E staining of hepatic sections established the occurrence of hepatocellular hypertrophy and steatosis in the MCD-fed groups. (B) Increase in body weight with time for C57BL/6 $(n=10)$ taken weekly from week 1-12 for all groups except for the MCD+PCB126 group where measurements were taken from week 1-8. The $\%$ increase in body weight gain with time was calculated and the body weight at week 1 was taken as $100 \%$. (C) Livers were weighed at euthanasia and the liver to bodyweight ratio was calculated. \% fat composition and $\%$ lean tissue were measured at the end of the study using the EchoMRI. Values are mean $\pm \mathrm{SEM}, * p<0.05$ versus CD-fed mice, $\# p<0.05$ versus MCD diet-fed mice, $\dagger p$ $<0.05$ versus CD-fed mice exposed to $\mathrm{PCB} 126, \uparrow \dagger p<0.05$ versus $\mathrm{CD}$-fed mice exposed to Aroclor1260. 
A

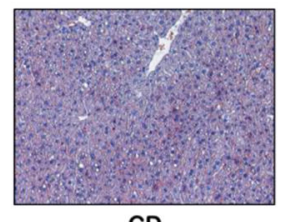

CD

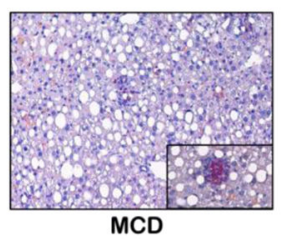

MCD

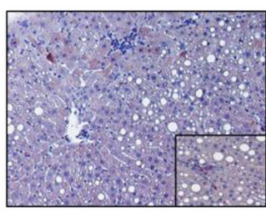

CD+PCB126

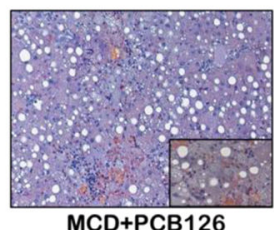

MCD+PCB126

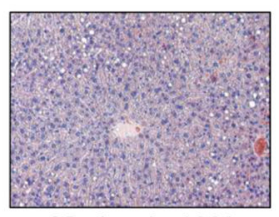

CD+Aroclor 1260

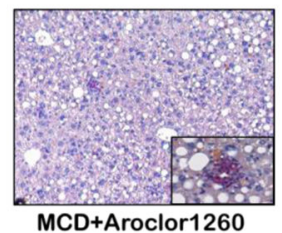

B

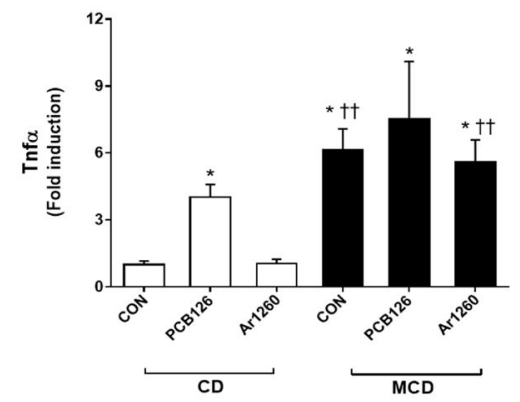

C

D

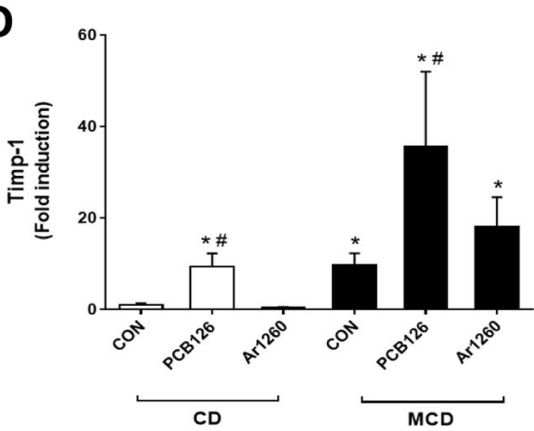

Figure 2. PCB126 and Aroclor1260 exposure worsened steatohepatitis caused by MCD feeding (A) CAE staining demonstrated neutrophil infiltration in the MCD-fed groups. Hepatic mRNA expression for (C) Tnfa and (D) PAI-1 and (E) Timp-1 were calculated. Values are mean $\pm \mathrm{SEM}, * p<0.05$ versus CD-fed mice, $\# p<0.05$ versus MCD diet-fed mice, $\dagger p$ $<0.05$ versus CD-fed mice exposed to PCB126, $\dagger \dagger p<0.05$ versus CD-fed mice exposed to Aroclor1260. 
A

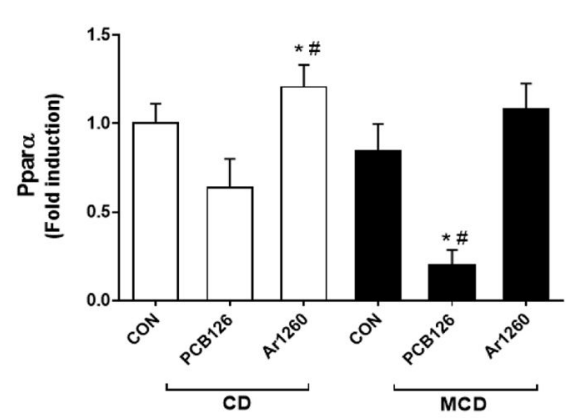

C

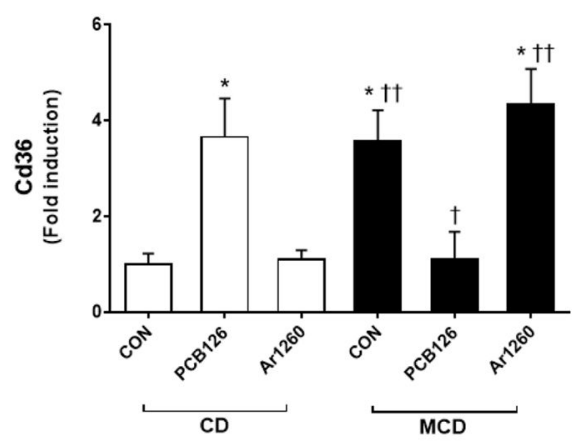

$\mathbf{E}$

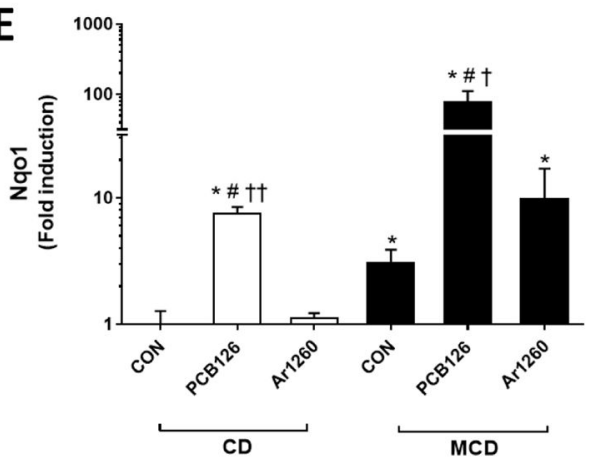

B

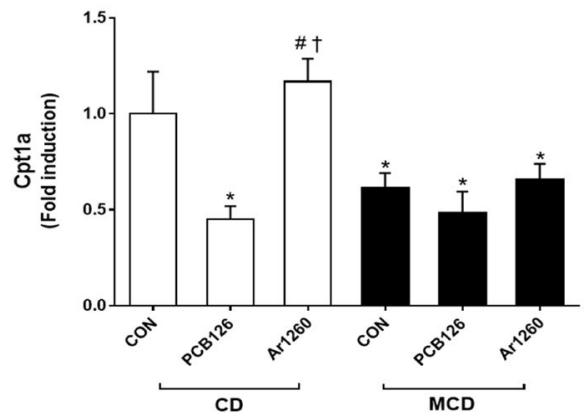

D

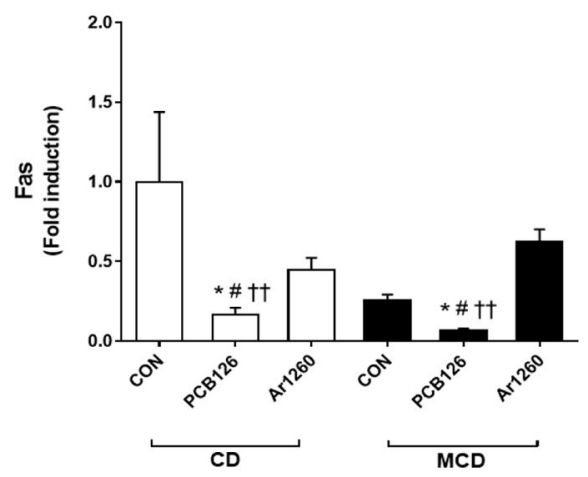

$\mathbf{F}$

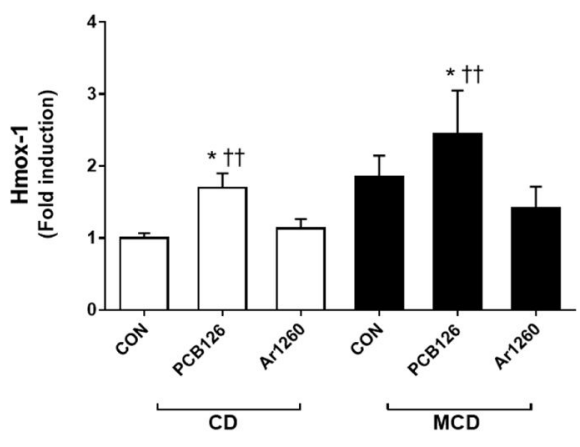

Figure 3. Effects of PCB126 and Aroclor1260 on expression of hepatic genes involved in endobiotic metabolism

Hepatic mRNA expression for (A) Ppara, (B) Cpt1a, (C) Cd36, (D) Fas, (E) Nqo1 and (F) Hmox- 1 were measured. Values are mean $\pm \mathrm{SEM}, * p<0.05$ versus $\mathrm{CD}$-fed mice, $\# p<0.05$ versus MCD diet-fed mice, $\dagger p<0.05$ versus CD-fed mice exposed to PCB126, $\dagger \dagger p<0.05$ versus CD-fed mice exposed to Aroclor 1260. 
A

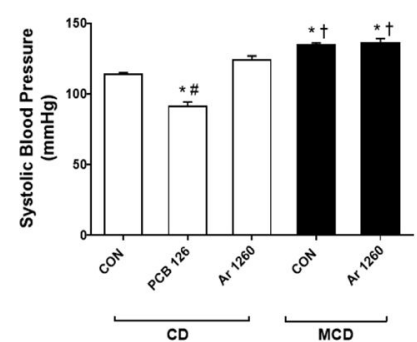

C

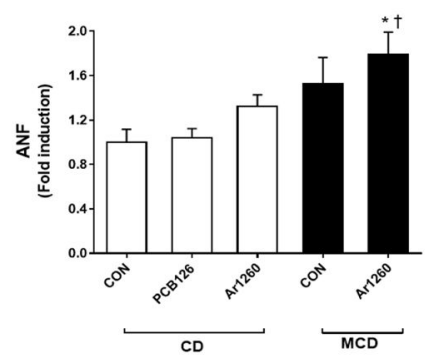

E

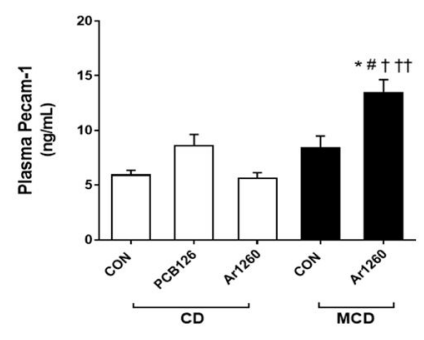

B

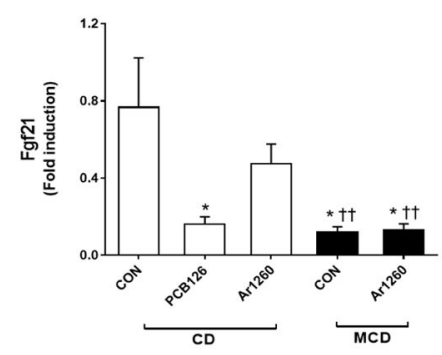

D

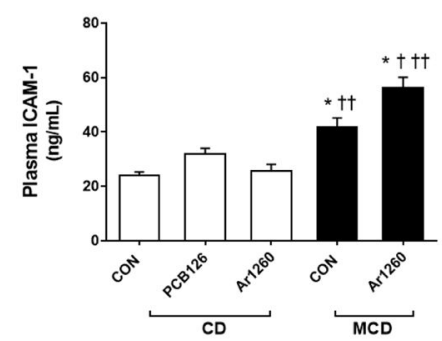

$\mathbf{F}$

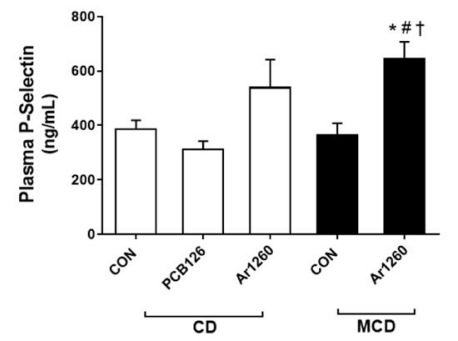

\section{G}

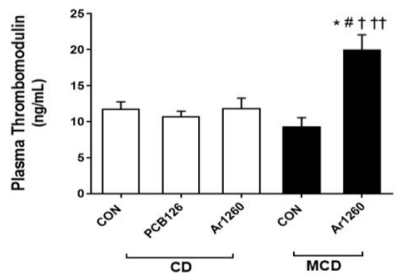

Figure 4. Effects of PCB126 and Aroclor1260 on blood pressure and cardiac gene expression (A) Systolic blood pressure was measured using a non-invasive tail-cuff system. The measurements were performed for four sequential days on week 11 of the study. Cardiac mRNA expression for (B) Fgf21 and (C) $A N F$ were measured. Plasma (D) ICAM-1, (E) Pecam-1, (F) P-Selectin and (G) thrombomodulin were measured using the MAGPIX system. Values are mean $\pm \mathrm{SEM}, * p<0.05$ versus $\mathrm{CD}$-fed mice, $\# p<0.05$ versus MCD diet-fed mice, $\dagger p<0.05$ versus CD-fed mice exposed to PCB126, $\dagger \dagger p<0.05$ versus CD-fed mice exposed to Aroclor1260. 
A

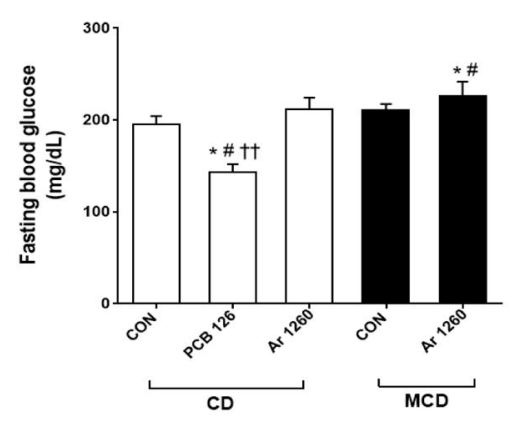

C

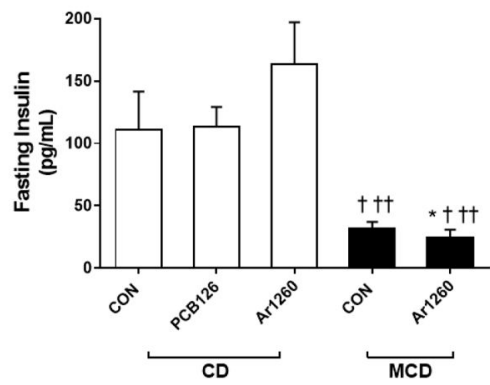

$\mathbf{E}$

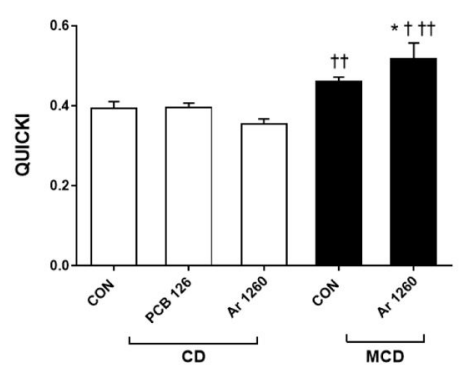

G

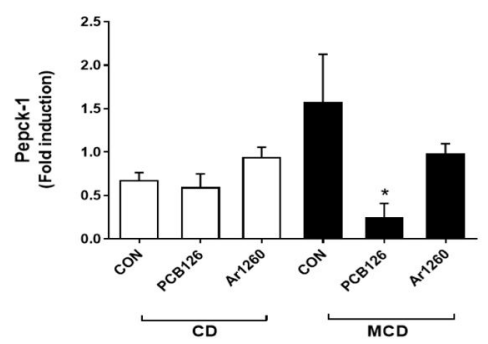

B

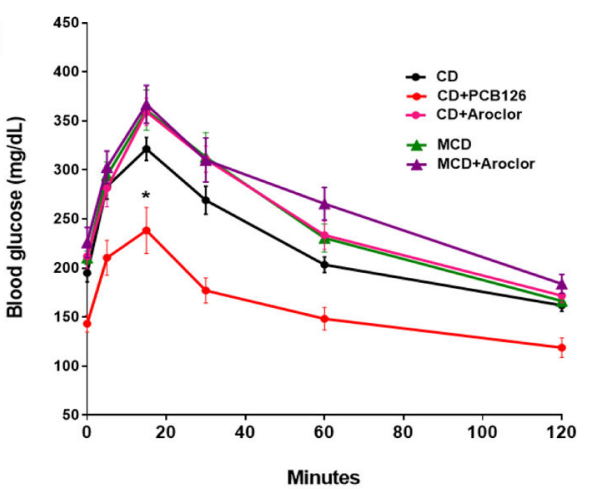

D

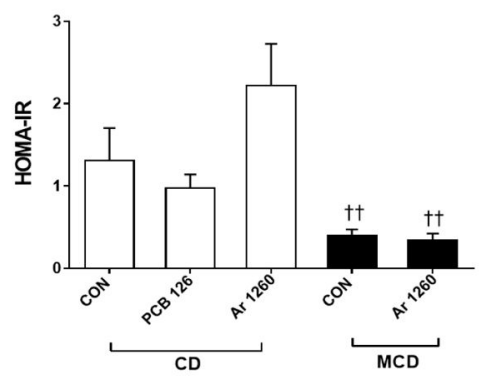

F

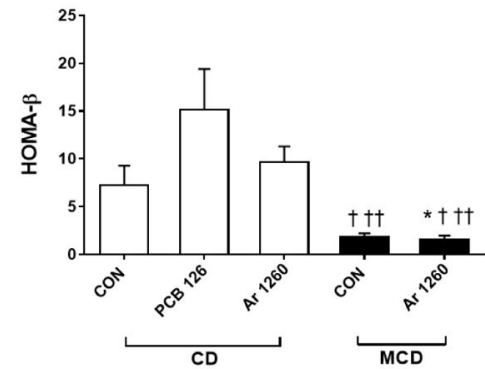

H

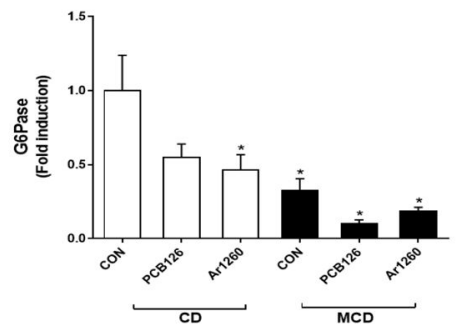

Figure 5. Effects of $\mathrm{PCB126}$ and Aroclor1260 in glucose metabolism and insulin resistance (A) Fasting blood glucose levels (mg/dL) were measured and (B) glucose tolerance test was performed. (C) Plasma insulin levels were measured using the MAGPIX system. (D) Homeostasis model assessment of insulin resistance (HOMA-IR) was calculated. (E) Quantitative insulin sensitivity check index (QUICKI) and (F) HOMA- $\beta$ which are indices for insulin sensitivity were calculated. Hepatic mRNA expressions for (G) Pepck-1 and (H) G6Pase were measured. Values are mean \pm SEM, $* p<0.05$ versus CD-fed mice, \# $p<0.05$ versus MCD diet-fed mice, $\uparrow p<0.05$ versus CD-fed mice exposed to PCB126, $\dagger \dagger p<0.05$ versus CD-fed mice exposed to Aroclor 1260. 
A

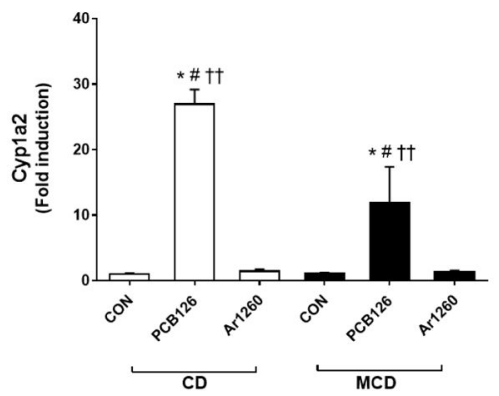

B

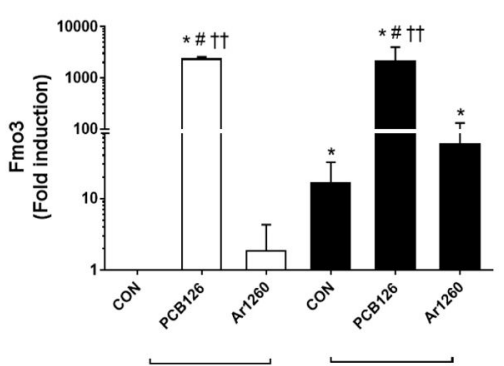

C

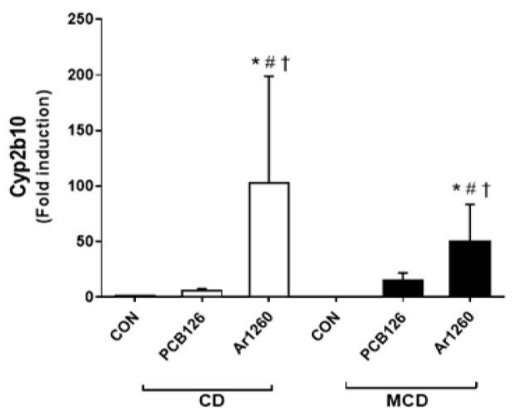

D

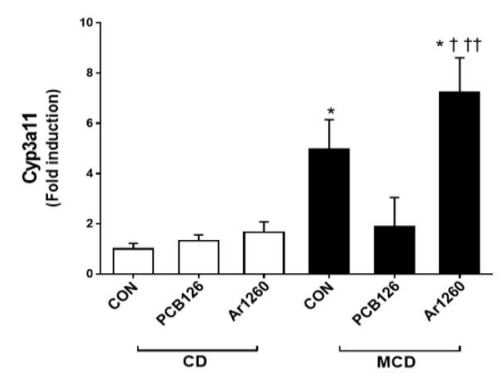

Figure 6. PCB126 and Aroclor1260 exposure altered hepatic expression of AhR, CAR and PXR target genes

Hepatic mRNA expressions for (A) Cypla2 (AhR target gene), (B) Fmo3 (AhR target gene), (C) Cyp2b10 (CAR target gene) and (D) Cyp3a11 (Pxr target gene) were measured. Values are mean $\pm \mathrm{SEM}, * p<0.05$ versus CD-fed mice, $\# p<0.05$ versus MCD diet-fed mice, $\uparrow p$ $<0.05$ versus CD-fed mice exposed to PCB126, $\dagger \dagger p<0.05$ versus CD-fed mice exposed to Aroclor 1260 . 